\title{
First light: old age psychiatry in Wolverhampton 1995-1996
}

\author{
David Jolley, Rosie Jenkins and Simon Dixey
}

In a survey of services conducted by the Section of Old Age Psychiatry in 1993, Wolverhampton was identified as one of 24 Districts with no consultant Old Age Psychiatrist in post (Benbow \& Jolley, 1996). This encouraged the newly formed NHS Trust responsible for mental health and other community services to arrange for the secondment of $D$. J. from South Manchester, for a period of two years, with a view to setting up and running an appropriate service for older people with mental illnesses (Jolley, 1996). We are reporting here some of the changes which have occurred during the first year of this secondment.

\section{Inheritance}

The adventure was timed to begin on 1 April 1995, with three days per week devoted to Wolverhampton. The departure of locum cover in February of that year necessitated a "broughtforwards', makeshift arrangement of 1-2 days per week for a few weeks, with support from a consultant colleague from the small pool of general psychiatrists. From April onwards, old age psychiatry has been self-sufficient, including a 24 hours on-call service.

The 30-bedded ward had six vacancies, the 30 placed day hospital was full (with a waiting list of 15) and out-patients were booked to a hospitalbased clinic 8-10 weekly and had often been seen by a trainee with nominal cover from other consultants. New referrals had been relatively few (4-6 weekly), often seen by trainees, on-call doctors or as domiciliary visits. Most older patients with established functional disorders remained under the care of a general psychiatrist, although their community psychiatric nurse (CPN) support might be from the specialist old age team.

\section{First moves}

It was agreed that all new referrals of older people and patients suffering from dementia at any age should be referred to the old age service. Referrals might be to the established CPNs or directly to D. J., and weekly meetings of the four sectorised CPN teams with D. J. became an essential component of the activity. D. J. became available to the CPNs and anyone else who needed support, 24 hours a day, every day, courtesy of mobile phone technology.

Review of the inherited in-patients revealed opportunities for their improvement by treatment and a very able and committed ward team. The prospect that patients could get better rather than be processed to 'placements' uplifted a few spirits.

Review of the 'waiting list' for the day hospital suggested that assessments could be better conducted in an out-patient clinic (Jolley \& Jolley, 1991), so the waiting list was terminated. An out-patient clinic was set up to allow full review of physical and mental health, including a physical examination, review of all medical and psychiatric notes, weight, urinalysis, blood test, $\mathrm{X}$-ray and where appropriate, electrocardiogram (ECG). The conduct of this clinic was enhanced by the involvement of members of the local branch of the Alzheimer's Disease Society (a 'first' for Wolverhampton as far as we are aware). All other out-patient activity was redesignated 'community out-patients' (Benbow, 1990), and all new referrals and follow-up contacts undertaken in the patient's home. This led to rather long clinics until appointments were rearranged to allow visits to be focused in one or two rather than all four sectors, but confirmed D. J.'s affection for the multivariate characteristics of this surprisingly attractive and engaging community.

There were no long-term care beds to use, look after or worry about, although the need for them was obvious and repeatedly confirmed by relatives of the most damaged patients. There was nothing for it but to learn about the existing system of residential and nursing homes, work with it and seek to improve matters as time allowed.

Liaison referrals offered the additional opportunity to meet colleagues in all disciplines in the four hospitals of the town and to grasp the culture and expectations of their wards and services. Junior medical staffing allocated two senior house officers to old age psychiatry, one 
of whom became unwell and took sick leave for six months.

\section{Added strengths}

Through the good and kindly offices of Dr Sami Gaspar, elder statesman and Clinical Tutor of West Midlands' Old Age Psychiatry, Rosie Jenkins and Simon Dixey chose to spend their Senior Registrar special interest sessions in Wolverhampton; Simon doubled his to pursue research. They brought fellowship, stimulation and energy, and the adventure acquired a broader smile. Rosie set about the day hospital and began a very productive relationship with colleagues in social services to understand, rationalise and redevelop day care/day hospital facilities on a town-wide basis. Simon took on an even more ambitious remit in residential/nursing home and hospital long-stay care, which he is reviewing and mapping systematically to provide a clear and firm understanding of the structure and dynamics of our inheritance. This knowledge-base will be a powerful resource as we begin to use long-stay NHS beds again, thanks to 'clarified' government requirements that all health authorities make available a sufficient ration of such beds according to agreed criteria (Department of Health, 1995).

Things were happening and this was persuasive medicine. Management have remained immensely supportive and by July we were able to advertise for a consultant, and appointed two. A decade of fruitless asking was over and Wolverhampton has its own source of illumination. From October 1995, we have functioned with four multidisciplinary Community Mental Health Teams for the Elderly (CMHTE), each consisting of a senior doctor (three consultants and a senior registrar), together with the specialist CPN teams. At present the teams liaise closely with social services; it is planned to include social work and other disciplines within the teams over the next few months. Referrals increased further, from 50-60 per month when $D$. J. was 'singlehanded', up to more than 80 per month, $80 \%$ being seen in their own environment within 2-3 days. Follow-up contacts have increased from 20 to more than 60 each week. Use of the day hospital remains disciplined with no waiting list. but the demand on beds for assessment and treatment has escalated since almost all older patients now come to the old age psychiatry service. Cross-referrals from other consultants are never refused and have amounted in some months to $25 \%$ of new contacts. Unsurprisingly, this has led to the need to borrow beds on other wards from time to time; no one would suggest that $\mathbf{3 0}$ acute beds is sufficient for a population of 40000 old people, especially given the absence of continuing care beds (Royal College of Psychiatrists, 1995).

Interactions with social services, geriatric medicine, general practice, private nursing homes and the voluntary agencies, particularly the Alzheimer's Disease Society, have grown stronger and happier. Weekly meetings with any interested parties, by a core group of likeminded gerontophiles in Beatties' tea shop, have provided the think-tank and driving force for further visions and developments.

\section{Spreading the light}

In a place which was uncomfortable in its famed state of mutual mistrust, a shared mental health strategy was produced by the Wolverhampton Health Authority in the autumn of 1995, with health purchaser, health provider, social services, general practice, users and carers contributing to and owning the product. Mental health services are being reshaped to a pattern predicted by the old age service template. This influence on the rest of mental health services and other community health services is a story in itself and may prove to be the most significant product of the exercise. The embryo of a university department has been spawned and this too will have a wider significance.

Others have been moved to undertake similar experiments to help places in difficulty. Susan Benbow has shown enormous resource and resilience to lead the way in West Cheshire while maintaining high standards in Central Manchester. Chris McWilliam has taken the plunge and moved from academic Keele to Walsall, where conditions have been at least as worrying as those in Wolverhampton.

This is a very difficult time for medicine as a whole and psychiatry in particular, since the demand for educated person-power far outstrips the supply. We have to balance the requirement to improve the quality of the best services and demonstrate what can be done beyond the barriers of previous good practice (Jolley, 1994), with the responsibility to shed light into every dark corner so that no sectors of the population are without the basics of help they should be receiving. The South Manchester/ Wolverhampton experiment demonstrates one way in which this can be achieved successfully. Perhaps other well developed (and resourced) services can be encouraged to offer a helping hand to weaker neighbours.

\section{References}

BENBOW, S. M. (1990) The community clinic: its advantages and disadvantages. International Journal of Geriatric Psychiatry, 5, 119-121. 
- \& JoulEY, D. J. (1996) A speciality register: uses and limitations. Psychiatric Bullettr, 20, 459-460.

DEPARTMENT OF HEALTH (1995) NHS Responsibilities for Continuing Health Care Needs. HSG(95)LAC(95)5. London: DoH.

JowEY, D. (1994) Realising a vision. Care of the Elderly. August, 306-307.

- (1996) Light into the darkness: bringing Old Age Psychiatry to unfashionable places. Psychiatric Bulletin, 20, 174-176.

JOLeY, S. P. \& JOLLEY, D. J. (1991) Psychiatric disorders in old age. In Community Psychiatry (eds H. Freeman \& D. Bennett), pp. 268-296. Edinburgh: Churchill Livingstone.

Royal College of Psychiatrists (1995) Caring for a Community: The Community Care Policy of the Royal
College of Psychiatrists (Council Report CR 36). London: Royal College of Psychiatrists.

*David Jolley, Honorary Professor of Old Age Psychiatry and Community Health Services, University of Wolverhampton, Penn Hospital, Wolverhampton WV4 5HN; Rosie Jenkins, Consultant in Old Age Psychiatry, and Simon Dixey, Consultant in Old Age Psychiatry. Wolverhampton Health Care, New Cross Hospital, Wolverhampton

*Correspondence

\section{The ECT Handbook}

\section{The Second Report of the Royal College of Psychiatrists' Special Committee on ECT Edited by C. P. Freeman}

This report is a practical set of guidelines for psychiatrists who will be prescribing or administering ECT. It covers clinical guidelines, administration of ECT, the law and consent to treatment. Nursing guidelines, a review of ECT machines and a checklist for good practice are also included. Appendices covering new developments will regularly be produced and distributed as inserts to this volume. There is a separate teaching video available to complement the text, priced $£ 30.00$.

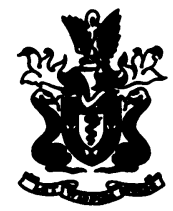

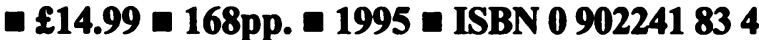

Available from the Publications Department, Royal College of Psychiatrists, 17 Belgrave Square, London SW1X 8PG (Tel. 0171-235 2351 extension 146) 